\title{
La tradición siriaca como intermediaria en la transmisión del pensamiento filosófico griego al entorno islámico: las Categorías de Aristóteles ${ }^{1}$
}

\author{
The Syriac tradition as an \\ intermediary in transmitting \\ Greek philosophy to the Islamic \\ context: Aristotle's Categories
}

\section{LUIS XAVIER LÓPEZ-FARJEAT**}

Resumen: El objetivo de este trabajo es registrar la relevancia de la tradición siriaca en la transmisión de la filosofía griega al entorno islámico. Con este fin, tras presentar aspectos histórico-filosóficos que enfatizan el papel de los traductores cristianos siriacos, me ocupo del impacto que tuvieron las Categorías, el tratado lógico de Aristóteles, en la conformación del vocabulario filosófico utilizado en la formulación del dogma trinitario en la tradición cristiana y en las discusiones acerca de los atributos divinos en la teología islámica. A través de estos dos ejemplos muestro la influencia de la tradición filosófica siriaca en algunos teólogos islámicos, y sostengo que la labor de traducción de los cristianos orientales fue notable en casos específicos.

Palabras clave: tradición siriaca; Aristóteles; Categorías; teología islámica; dogma trinitario; atributos divinos.

Recepción: 26 de noviembre de 2017. / Aceptación: 19 de febrero de 2018.

* Universidad Panamericana, 1lopez@up.edu.mx

${ }^{1}$ Esta investigación forma parte del proyecto "Metodologías de interpretación de Tanaj y Corán en las tradiciones clásicas judía e islámica”, financiado por la Universidad Panamericana a través del "Fomento a la Investigación UP 2017", código UP-CI-2017-FIL-MX-02. 
Abstract: The aim of this paper is to examine the importance of the Syriac tradition in transmitting Greek philosophy to the Islamic context, starting with an introduction of some historical-philosophical aspects emphasizing the role of Christian Syriac translators. This is followed by a study of the impact of Aristotle's Categories on the creation of the philosophical vocabulary used to formulate the Trinitarian dogma in the Christian tradition, and on the discussions concerning divine attributes within Islamic theology. Through these two examples, I reveal how the Syriac philosophical tradition influenced some Islamic theologians, and argue that the translation work done by Eastern Christians was remarkably important in specific cases.

Key words: Syriac tradition; Aristotle; Categories; Islamic theology; Trinitarian dogma; divine attributes.

\section{Introducción}

La importancia de la tradición intelectual islámica en la recepción, desarrollo y transmisión de la filosofía griega -en especial de Aristóteles- en el mundo europeo medieval es un hecho constatado por historiadores de la filosofía y de las ideas. ${ }^{2} \mathrm{El}$ papel de los filósofos islámicos no se reduce a la mera paráfrasis o conservación de los textos antiguos; también concibieron una filosofía original, capaz de enfrentar problemas propios del entorno islámico. Sin su labor intelectual, como se sabe, la preservación del pensamiento filosófico griego se habría visto interrumpida. La filosofía medieval europea es inimaginable sin los referentes grecoislámicos. Basta con analizar el modo en que teólogos cristianos como Alberto Magno o Tomás de Aquino, por mencionar sólo dos nombres, heredaron los argumentos y el vocabulario filosófico de pensadores como Alfarabi, Avicena, Avempace y Averroes, a través de las traducciones latinas hechas desde el siglo XII en la Escuela de Toledo. ${ }^{3}$ Más allá

${ }^{2}$ Existe abundante literatura al respecto. Véase, por ejemplo, Zimmerman y Craemer-Ruegenberg, 1985; D’Alverny, 1994; Butterworth y Blake, 1994; Fidora y Polloni, 2017; para conocer el modo en que la influencia islámica continuó durante el Renacimiento, véase Hasse, 2016.

${ }^{3}$ Por mencionar unos cuantos ejemplos, incluidos algunos sobre tratados específicos de los árabes: Daiber, 1999; Hasse, 2000; Fidora, 2003; Burnett, 2005; Janssens, 
de los acuerdos y desacuerdos doctrinales entre las dos tradiciones religiosas, el modo en que los conceptos y los argumentos de los filósofos islámicos se analizaron, se asimilaron y se adoptaron al contexto cristiano, es prueba de un riquísimo encuentro intelectual en el que, como es lógico, también hubo disenso, debate y crítica.

A pesar de la evidencia textual y la inabarcable cantidad de literatura especializada que permite constatar el modo en que la Europa medieval heredó la filosofía islámica y la judía, en 2008 el historiador Sylvain Gouguenheim (2008) publicó un libro titulado Aristote au Mont Saint-Michel: les racines grecques de l'Europe chrétienne, ${ }^{4}$ donde niega que la civilización islámica haya sido capaz de asimilar la filosofía y la ciencia griegas, y sostiene que fueron cristianos como Jacobo de Venecia (siglo XI) y los monjes cristianos del Mont Saint-Michel, quienes verdaderamente tradujeron y cultivaron la filosofía activamente, frente a un islam más bien anquilosado y reacio al cultivo de las disciplinas filosóficas. Gouguenheim intenta mostrar que en realidad la Europa cristiana jamás perdió su filiación griega, aunque admite que en Bizancio se vio seriamente disminuida, entre otras razones por el desuso de la lengua griega.

A pesar de lo anterior, insiste en que la traducción de textos filosóficos del griego al latín se mantuvo de manera constante, lo que restó importancia a la enorme cantidad de traducciones árabes que vieron la luz en Bagdad, en la Casa de la Sabiduría, de los siglos IX al XI, y que habrían sido heredadas a Europa (Gutas, 1998; Bruns, 2003; D’Ancona, 2010). En efecto, la Casa de la Sabiduría fue la cuna de la filosofía islámica. Se sabe que ahí se traducían y estudiaban tratados no sólo filosóficos, sino también de otras disciplinas como las ciencias religiosas, la alquimia, la astronomía, las matemáticas, la medicina, la historia, la geografía. El aprendizaje de la lógica aristotélica en ese centro del saber era primordial e indispensable para el cultivo de la medicina y la astronomía. Ahí fue donde los “árabes" -entre quienes había cristianos y musulmanes- lograron asimilar

2007; Bertolacci, 2009, 2011; Burnett, 2001; Hasse y Bertolacci, 2012; Schmieja, 2012; Fidora, 2013; Galluzzo, 2013; Hasse, 2014.

${ }^{4}$ Las reacciones al libro de Gouguenheim no se hicieron esperar; véase Büttgen, De Libera, Rashed y Rosier-Catach, 2009. 
la filosofía -en especial a Platón, Aristóteles, los estoicos y varios neoplatónicos-; ahí adaptaron la filosofía a su propio contexto; ahí le llamaron falsafa a la filosofía; ahí se gestó el pensamiento de al-Kindī, el primer filósofo de los árabes, y su círculo (Endress, 1997a).

La Casa de la Sabiduría era un centro interreligioso donde confluían principalmente musulmanes, musulmanes conversos y cristianos orientales. El entorno era, además, plurilingüístico, ya que en él circulaban textos escritos en griego que se traducían al siriaco y, en algunos casos, al persa, y posteriormente al árabe. El siriaco era el dialecto del arameo utilizado, junto con el griego, por buena parte de los cristianos orientales. ${ }^{5}$ Por ello, vale decir que en los procesos de traducción del siriaco al árabe, dos lenguas con algunas similitudes, también se transmitieron algunos aspectos conceptuales de raíz grecocristiana que, de alguna forma, marcan la filosofía y la teología islámicas (Brock, 1984b; Huggonard-Roche, 1990; Penn, 2015). Traducir un texto es en parte un acto de apropiación lingüística y cultural, y en las traducciones los textos terminan por adquirir nuevos sentidos y nuevas formas de entenderse e interpretarse. La apropiación de la terminología griega y siriaca en la literatura filosófica y teológica de los cristianos orientales y los musulmanes es particularmente desafiante y, lejos de formular teorías generales, cada texto en particular requiere una revisión minuciosa. Sólo de este modo es posible determinar los aspectos específicos desde los que puede reconocerse y trazarse una historia conceptual que, en muchos casos, permitiría reconocer raíces filosóficas en común y, como consecuencia, referentes conceptuales muy similares en tradiciones distintas. En esta dirección, es cierto que los cristianos orientales desempeñan un papel importante en el proceso de transmisión y difusión de los textos filosóficos griegos a la civilización islámica y, posteriormente, al cristianismo latino y a Europa en general.

En el capítulo segundo de su libro, Gouguenheim destaca precisamente el papel de los traductores cristianos de Oriente y sostiene que, entre los siglos VII y x, la cultura árabe-islámica fue más bien marginal, y que quienes verdaderamente tradu-

${ }^{5}$ De hecho, el siriaco heredó varios términos griegos. Véase Brock, 1984a. 
jeron y trabajaron con los textos filosóficos griegos fueron los cristianos orientales. En efecto, los cristianos de Oriente - siriacos, jacobitas, melquitas, coptos, nestorianos, maronitas, sabeos (Brock, 1992) - fueron traductores del griego al siriaco y, posteriormente, tras el dominio musulmán, del siriaco al árabe (y, en algunos casos, directamente del griego al árabe).

Gouguenheim señala en particular la labor de tres personajes sin duda importantes en el siglo IX: Hunayn ibn Ishāq (nestoriano), Teodoro Abū Qurrah (melquita) y Yuhanna ibn Masawaih (nestoriano). ${ }^{6}$ Ensalza, con justa razón, la labor de estos traductores y pensadores, y concluye de manera terminante que la civilización islámica debe prácticamente todo a los cristianos de Oriente, algo que, según su visión, suele pasarse por alto al difundirse la versión comúnmente aceptada de que Europa debe al islam su desarrollo civilizatorio, cuando, en realidad, según Gouguenheim, se lo debe a los cristianos de Oriente.

La radicalidad de esta conclusión, aunada a la falta de conocimiento de la tradición cristiana oriental y de la filosofía islámica, además de un manejo deficiente de los estudios especializados en la materia, como por ejemplo los de Alain de Libera ${ }^{7}$ (a quien ataca recurrentemente), 'Abdurrahmān Badawī (1968) o Mohammed Arkoun (1982; 2005), entre otros, hacen que las equivocaciones y las visceralidades del libro sobresalgan por encima de una premisa que, a mi juicio, podría no ser tan descabellada si se comprende de manera matizada y en su justa medida: es verdad que los cristianos de Oriente y sus traducciones siriacas desempeñan una función importante en el proceso de transmisión de la filosofía griega al mundo islámico; sin embargo, es indispensable definir con la suficiente especificidad cuál fue el papel de la lengua siriaca como inter-

${ }^{6}$ Hay literatura suficiente en la que se reporta la relevancia de estos tres personajes. Para el caso de Hunayn ibn Ishāq, véase la colección de artículos reunidos en Sezgin, 1999; sobre Teodoro Abū Qurrah, véase Monferrer Sala, 2005; y para Yuhanna ibn Masawaih, véanse los artículos reunidos en Sezgin, 1996.

${ }^{7}$ Es enorme la cantidad de literatura especializada en la que De Libera ha hecho notar la influencia de los filósofos árabe-islámicos en la filosofía medieval latinocristiana y la conformación de la Europa moderna. No remito aquí a uno de sus múltiples trabajos académicos, sino a una entrevista donde es explícito al respecto; a saber: De Libera, 1997. 
mediaria entre el griego y el árabe. ${ }^{8}$ Eso es precisamente lo que intentaré mostrar en este artículo. En lo que sigue me ocuparé de algunas cuestiones histórico-filosóficas con la finalidad de asentar la relevancia de los cristianos orientales en la difusión y la transmisión de la tradición intelectual griega. Seré cuidadoso, pues si bien defiendo que la labor de los cristianos de Oriente es crucial en el proceso de construcción y evolución de determinados conceptos filosóficos -sobre todo lógicos y metafísicos-, de ello no se sigue que la tradición intelectual islámica haya sido estéril, como infiere Gouguenheim.

Me parece más adecuado atender el proceso de adaptación y transmisión del vocabulario filosófico griego al siriaco, al persa, al árabe, al hebreo y al latín como un fenómeno en constante flujo, donde los términos van siendo cada vez más refinados y precisos. El modo en que se utilizan las palabras en cada texto y en cada lengua obliga a un minucioso trabajo de análisis e interpretación. Si bien la traducción remite al texto de salida -escrito en griego-, ésta adquiere una identidad propia con sus respectivas complejidades. En este sentido, el Aristóteles griego es distinto del Aristóteles siriaco (Baumstark, 1900) y del Aristóteles árabe (Endress, 1997). Aun cuando el Aristóteles siriaco y el árabe remiten al griego y dependen de él, los textos en las lenguas nuevas guardan cierta distancia y adquieren cierta autonomía frente al original. Sin embargo, puesto que traducir también es interpretar, es posible que en alguna medida la traducción - una buena traducción- contribuya a la comprensión y el esclarecimiento del sentido del propio texto de salida. El traductor da a conocer un escrito generando uno nuevo. Por ello, aunque la mediación siriaca en la transmisión de textos griegos al mundo árabe-islámico es crucial, la labor de traducción e interpretación se mantiene activa cuando el siriaco pasa al árabe o el árabe al latín y al hebreo. El caso del hebreo es particularmente ilustrativo: Maimónides, el judío, redactó su obra capital, La guía de los perplejos, en árabe. No lo hizo así sólo porque la escribió en tierras islámicas, sino porque para entonces el hebreo carecía de vocabulario filosófico, mientras

\footnotetext{
${ }^{8}$ Véase Takahashi, 2015. Para el caso del Órganon de Aristóteles, véase Huggonard-Roche, 1991.
} 
que el árabe lo había ya adaptado y asimilado. Hasta que Samuel ibn Tibbon tradujo a Maimónides del árabe al hebreo, pudo constituirse un vocabulario filosófico propio para la filosofía judía. Nadie diría que la filosofía de Maimónides es árabe y no judía por haber sido concebida en árabe.

Con la finalidad de mostrar la relevancia de la labor de los cristianos orientales en la difusión y la transmisión de la filosofía griega al mundo árabe-islámico —en especial de la lógica-, tras presentar antecedentes históricos sobre todo, me ocuparé brevemente de un ejemplo teológico a partir del cual se puede constatar la importancia de los cristianos orientales en la adaptación y la composición del vocabulario filosófico que poco después se utilizaría entre filósofos y teólogos tanto cristianos como musulmanes. Me refiero a la discusión en torno a los atributos de Dios y el papel que tuvo un tratado lógico de Aristóteles, las Categorías, para resolver el problema de los predicados atribuidos a Dios sin sacrificar su simplicidad y su unidad. Por una parte, el vocabulario y los recursos conceptuales de Aristóteles y los neoplatónicos sirvieron para que los cristianos argumentaran que el dogma trinitario -un único Dios con tres hipóstasis-, promulgado en el Concilio de Nicea (325), ampliado en el de Constantinopla (381) y discutido en el de Éfeso (431) y en el de Calcedonia (451), no ponía en riesgo la simplicidad de Dios. Por otra parte, los musulmanes utilizaron siglos más tarde el mismo texto aristotélico para mostrar la incoherencia del dogma trinitario y establecer la simplicidad absoluta en Dios. No obstante, al conocer los argumentos cristianos a favor de la Trinidad, algunos teólogos musulmanes se percataron de que el vocabulario y los argumentos utilizados por sus contrincantes servían para resolver un problema compartido por las tres religiones monoteístas; a saber: el de los atributos divinos. Mostraré que las Categorías de Aristóteles, en su versión siriaca, no sólo fueron esenciales para la formulación conceptual del dogma trinitario, sobre todo cuando los cristianos orientales lo defendieron en tierras islámicas, sino que también proporcionaron a los musulmanes referentes lógico-metafísicos para formular una doctrina conveniente de los atributos divinos. 


\section{Antecedentes históricos: la traducción del Órganon}

En años recientes, la edición de algunos textos y publicaciones notables sobre la importancia de los cristianos de Oriente ha llamado la atención entre algunos académicos interesados en reconstruir la recepción y la difusión de determinados tratados, principalmente filosóficos y médicos, esenciales para comprender en detalle los procesos de adaptación y adopción de la filosofía griega en el entorno cultural cristiano de Medio Oriente y en el islámico. ${ }^{9}$ El siriaco, utilizado principalmente por los cristianos, fue la lengua semítica mediadora entre el griego y el árabe. En consecuencia, las traducciones siriacas son un eslabón importante para comprender el sentido y la interpretación de conceptos filosóficos en lengua árabe.

Pocos estudiosos se han ocupado de este episodio en la historia conceptual y el modo en que repercute en la comprensión de la filosofía griega, quizá de manera más notoria en la transmisión del corpus aristotélico y en las obras médicas de Galeno. Es bien sabido que Aristóteles fue el pensador griego de mayor impacto entre los filósofos, los teólogos y los juristas islámicos durante el periodo abasí (750-1258), en el que floreció la Casa de la Sabiduría.

La filosofía aristotélica era, en buena medida, el método científico de aquellos tiempos. El modo en que la filosofía de Aristóteles llegó a los musulmanes es bastante conocido y, para comprenderlo, hay que remontarse a los primeros siglos del cristianismo, antes de que el islam apareciera en el panorama histórico. Los monofisitas, los ortodoxos y los nestorianos fueron sectores cristianos siriacos, protagonistas centrales de las disputas generadas en los primeros siglos del cristianismo, cuando se buscaba determinar la naturaleza de Cristo. Los monofisitas enseñaban que Dios y el hombre estaban unidos en una sola naturaleza a través de Cristo; en cambio, los ortodoxos y los nestorianos distinguían entre una naturaleza divina y una humana. La cuestión que los dividía era, en concreto, si en Cris-

${ }^{9}$ Por mencionar algunos ejemplos, véase Takahashi, 2003; Joose, 2004; Watt, 2005; Brock, 2007; Vagelpohl, 2008, 2010; Schmitt, 2013; Treiger, 2014; y habría que añadir las versiones de las Categorías a las que me refiero más adelante. 
to la voluntad y los actos humanos y divinos se identificaban o no. Los monofisitas sostuvieron la unidad de Cristo afirmando exclusivamente su naturaleza divina y descartando su naturaleza humana; los nestorianos afirmaron, en cambio, que en Cristo había dos naturalezas, la humana y la divina, distintas y separadas, y que correspondían a dos personas distintas en Cristo. Este problema teológico derivó en discusiones filosóficas en las que destacaron, precisamente, los nestorianos. ${ }^{10}$ Éstos se habían establecido en Antioquía, Persia y Mesopotamia, donde cultivaron la filosofía desde el siglo v. Cuando los musulmanes invadieron esos territorios en el siglo vII, conocieron las obras teológicas desviadas del catolicismo de Calcedonia ${ }^{11}$ y las traducciones de filosofía griega que los siriacos nestorianos habían comenzado a hacer.

Yendo un poco más atrás, recuérdese que, en 489, Flavio Zenón, el emperador bizantino, cerró la escuela de Edesa, un sitio precisamente con tendencias nestorianas donde se cultivaba la teología, la filosofía y otras disciplinas. Tras dicho acontecimiento, los nestorianos perseguidos se trasladarían a Nísibis y territorios aledaños. Poco tiempo después, en 529, el emperador Justiniano ordenó el cierre de la Escuela de Atenas por difundir ideas paganas. Los filósofos que enseñaban ahí se trasladaron hacia otros territorios dominados por el imperio persa, específicamente la zona donde hoy se ubican Irán, Siria, Iraq y Turquía. Se suma, además, que desde mediados del siglo III los persas habían vencido a los romanos y trasladado a varios esclavos, entre éstos algunos griegos, hacia territorios persas. La presencia de griegos y nestorianos asirios que conocían la lengua griega y la filosofía fue esencial para el nacimiento de la escuela de Jundaysābūr (Schöffler, 1980). Cosroes I (501-579), rey de la dinastía sasánida del segundo Imperio persa, permitió que los filósofos griegos y nestorianos continuaran su labor. Cosroes encargó la elaboración de traducciones del griego al siriaco y

${ }^{10}$ Véase Abramowski y Goodman, 1972. Ese trabajo consta de dos volúmenes: el primero contiene la selección de textos en siriaco y el segundo, las traducciones.

${ }^{11}$ En el Concilio de Calcedonia en 451 se estableció que en Cristo hay dos naturalezas (una humana y una divina), aunque una sola persona y una sola voluntad. Tras el establecimiento de este dogma, el cristianismo se dividió entre quienes estaban a favor de Calcedonia y quienes estaban en su contra. 
también al persa sasánida, este último conocido como pahlavi o persa medieval.

Jundaysābūr se convirtió en centro de enseñanza y traducción no sólo de filosofía, sino también de otras disciplinas como medicina, astronomía, matemáticas y otras más. Poco antes del periodo abasí (750-1258) ya existían, junto con Jundaysābūr, varias escuelas en las que se cultivaba la filosofía: en Harrán, una ciudad ubicada entre lo que hoy conocemos como Turquía y Siria, había una escuela neoplatónica; había, además, escuelas en las que enseñaban maestros cristianos nestorianos, cristianos monofisitas, persas y alejandrinos en las ciudades de Alejandría, Antioquía y Nísibis, y algunas regiones de Siria, Asia Menor y Mesopotamia. Cuando en el siglo vil los musulmanes conquistaron Siria y Mesopotamia (638), Egipto (640) y Persia (641), entraron en contacto con los textos científicos y filosóficos que había en aquellos territorios (Hourani, 1991, pp. 7-97). Varias traducciones de estas obras se remontan, como puede verse, al periodo preabasí, en el que la mayor parte de los traductores eran cristianos o musulmanes recién convertidos. La producción de traducciones al árabe se volvió cada vez más intensa en el califato de al-Mansur (del 754 al 775) y se extendió hasta el de al-Ma'mūn (del 813 al 883). Para el siglo Ix, en pleno entorno cultural islámico, floreció en Bagdad la Casa de la Sabiduría, uno de los centros más prolíficos de traducciones auspiciado por al-Ma'mūn, y un lugar en el que colaboraban traductores cristianos nestorianos con pensadores y científicos musulmanes.

En Bagdad se tradujeron obras y fragmentos de filósofos como Empédocles, Pitágoras, Platón, por supuesto Aristóteles, Teofrasto, Alejandro de Afrodisia, Porfirio, Plutarco, Proclo, Plotino, entre otros; de matemáticos como Arquímedes, Apolonio, Menelao, Ptolomeo; de obras médicas de Hipócrates y Galeno, entre muchas otras. De la gran cantidad de tratados que circularon en Bagdad, destaca el Órganon de Aristóteles (Brock, 1993; Huggonard-Roche, 1993). En el caso de esta colección de tratados lógicos se distinguen varias etapas en el proceso de traducción del griego al siriaco y del siriaco al árabe que abarcan aproximadamente un periodo que corre del siglo $\mathrm{V}$ al siglo $\mathrm{x}$ (Laughlin, 1995, pp. 104-112). En una primera etapa, entre los si- 
glos V y VII, se hicieron las primeras traducciones del griego al siriaco a cargo de cristianos como Probus de Antioquía, quien tradujo las Categorías, Sobre la interpretación y los Analíticos primeros; Atanasio de Badi (m. 686), patriarca de Antioquía de la iglesia ortodoxa siriaca y estudiante de Jacobo de Edesa (m. 708) en el monasterio de Quinnasrin, tradujo los Analíticos primeros y los Tópicos; Jorge de Kufa (m. 724), obispo de los árabes, un ortodoxo monofisita/jacobita, tradujo también las Categorías, Sobre la interpretación y los Analiticos primeros. Entre los siglos VIII y IX se inaugura una segunda etapa con las primeras traducciones del siriaco al árabe hechas por personajes como el patriarca nestoriano Timoteo I (m. 823), el erudito Ibn al-Bitrīq (m. 830) y Ayyūb ibn al-Qasim de Raqqah (m. 840), este último el único que aparentemente no era cristiano. Ibn al-Bitrīiq hizo traducciones de las Categorías y los Analíticos primeros, y al-Qasim, de la Isagoge; a Timoteo le debemos la primera traducción de los Tópicos. Esta etapa coincide con la primera fase de traducciones del siriaco al árabe.

En la tercera etapa (segunda fase de traducciones del siriaco al árabe), desarrollada hacia la segunda mitad del siglo IX, se perfeccionaron los métodos de traducción, en algunos casos se elaboraron paráfrasis y epítomes, pero la contribución más importante fue la integración de comentarios de Galeno, Amonio, Temistio y Alejandro de Afrodisia a los textos de Aristóteles. A esta etapa pertenecen los traductores más destacados, que, además, ya conocían a la perfección las tres lenguas, el griego, el siriaco y el árabe y, por lo tanto, trataron el texto griego de manera crítica y mucho más analítica, intentando capturar su significado y evitando la literalidad. En algunos casos tradujeron del griego al árabe y en otros siguió mediando el siriaco. ${ }^{12}$ Hunain ibn Ishaq (m. 877), su hijo Ishaq Ibn Hunain (m. 910) y Thābit ibn Qurrah (m. 901) ${ }^{13}$ son figuras esenciales en esta etapa en la que habría que destacar dos aspectos importantes: i) nos encontramos con traductores multilingües preocupados por comprender el sentido y el significado de los textos, y, por

${ }^{12}$ Ése habría sido el caso de la Retórica de Aristóteles, que se habría traducido precisamente en esta etapa. Véase Vagelpohl, 2008.

${ }^{13}$ Véase Rashed, 2009. Este volumen incluye información relevante para la recepción de Aristóteles. 
lo tanto, sus traducciones son al mismo tiempo interpretaciones que contribuyen a una mejor comprensión de los textos, y ii) la inclusión de Galeno y los comentadores de la antigüedad tardía influye directamente en la manera de comprender los textos filosóficos y científicos, puesto que estos comentadores habían integrado a su comprensión de Aristóteles aspectos provenientes de la tradición neoplatónica y también estoica.

En una cuarta etapa (tercera fase de traducciones del siriaco al árabe), a lo largo de la segunda mitad del siglo x, se hicieron nuevas y mejores traducciones, incluidas por fin la versión árabe de los Analíticos posteriores y de la Poética. Los traductores eran ahora también filósofos y, por lo tanto, capaces de elaborar sus propios comentarios. En esta etapa destacan figuras como Abū Bishr Mattā y Yahya ibn 'Adī, dos cristianos, uno maestro de lógica de uno de los más grandes filósofos de la tradición intelectual islámica, al-Fārābī, conocido como el "segundo maestro" -el primero era Aristóteles-, y el otro su discípulo (Watt, 2008, 2010).

En todo este proceso de traducción, Hunain ibn Ishaq fue el traductor nestoriano más destacado en la transmisión de textos médicos y filosóficos griegos a la cultura siriaca y a la árabe. Hunain provenía de una comunidad cristiana que, en medio de la presencia musulmana, se mantuvo fiel al cristianismo nestoriano. Se sabe que desde pequeño fue bilingüe: aunque el árabe era su lengua materna, su educación religiosa fue en siriaco, la lengua litúrgica de los nestorianos. En su juventud se trasladó a Bagdad para estudiar medicina (Ibn Abū Ușaybi'a, 1965, pp. 257-259; Bergstrasser, 1913; Cooperson, 1997; Strohmaier, 2012). Harto de las preguntas incómodas y complejas que solía formular, su maestro Ibn Māsawayh lo expulsó de la clase. Hunain se ausentó por más de dos años. Se desconoce a dónde fue exactamente, aunque algunas fuentes mencionan que viajó a Alejandría. A su regreso, su manejo del griego era sorprendente y se apunta en sus biografías que podía recitar a Homero en su lengua original. Fue entonces cuando se reconcilió con su maestro y comenzó a hacer traducciones de Hipócrates y Galeno para él. Tradujo al siriaco y al árabe más de cien obras médicas y varios textos filosóficos, e incluso el Antiguo Testamento, al siriaco. 
En la Epistola dirigida a 'Alī ibn Yabya sobre el conocimiento acerca de las obras traducidas y no traducidas de Galeno, encontramos algunas observaciones acerca de su metodología filológica, muy cercana a la nuestra (Strohmaier, 2012; Bergstrasser, 1925, 1932). En efecto, en dicha epístola, Hunain ofrece un listado bastante detallado de los libros de medicina y filosofía que tuvo a la mano, e incluye una breve explicación acerca de las partes que constituyen cada libro, así como de su contenido. En algunos informa sobre los distintos manuscritos en griego y en siriaco que había logrado conseguir, y explica que solía comparar las distintas versiones con la finalidad de establecer una lo suficientemente sólida antes de comenzar a traducir. ${ }^{14}$ De este modo, Hunain fungió también como editor de los textos sobre los que trabajó.

En lo que respecta a los tratados lógicos, tradujo del griego al siriaco las Categorías de Aristóteles junto con el comentario de Porfirio, los Tópicos con los comentarios de Amonio y Alejandro de Afrodisia, las Refutaciones sofísticas, Sobre el número de los silogismos de Galeno y los Analíticos posteriores de Aristóteles. Del griego al árabe tradujo el comentario de Amonio a la Isagoge, la Introducción a la lógica de Galeno, el comentario a las Categorías de Temistio, el comentario a Sobre la interpretación de Galeno, Sobre la demostración y Sobre las definiciones también de Galeno, y los comentarios de Amonio y Alejandro de Afrodisia a los Tópicos. Al parecer, revisó una traducción de los Analíticos primeros y posiblemente redactó un epítome a Sobre la interpretación (Anawati y Iskandar, 1978; Laughlin, 1995, p. 106).

La relevancia de Hunain no se limita a su papel como editor $\mathrm{y}$ traductor, sino que su trabajo interpretativo de esos textos le permitió comprender a fondo la naturaleza propia de la filosofía, es decir, como una disciplina científica neutral. Me explico: en el contexto en que vivió Hunain, era usual que la filosofía se utilizara como instrumento para la apologética. Hunain, en cambio, era un académico. Le importaban algunos asuntos teológicos, pero le interesaban más las disciplinas científicas, la

${ }^{14}$ Véase Bergstrasser, 1925, párrs. 2, 17, 18, 20, 74, 84, 39, 115, por citar algunos ejemplos. Para mayor información sobre el método de Hunain y el de otros traductores, véase Brock, 1984, y Griffith, 2008. 
medicina y la filosofía, y desde ahí obtuvo el reconocimiento de cristianos y musulmanes.

Los traductores como Hunain no suelen ser aceptados, salvo en muy pocos casos, como verdaderos filósofos. Sin embargo, fueron los adaptadores de buena parte del vocabulario filosófico utilizado en las controversias teológicas. Empero, a riesgo de ser repetitivo, insisto en que este vocabulario está en construcción, y las mismas palabras y sus conceptos cambian, se reinventan, adquieren nuevos sentidos y connotaciones en distintos contextos. Por ello, el traductor, el filósofo, el teólogo, habían de ser cautelosos con las palabras, especialmente al discutir problemas teológicos como, por ejemplo, los relacionados con la naturaleza divina, un tema de interés tanto para cristianos como para musulmanes.

\section{Las Categorías en la discusión acerca de la simplicidad divina y los atributos de Dios}

El tema de la simplicidad divina o de la unidad divina (tawhicd) y de los atributos divinos (sifāt) es crucial en la teología islámica, así como uno de los temas más controvertidos desde las discusiones teológicas más tempranas (Wolfson, 1959, 1976; Adamson, 2003; El-Bizri, 2008; Gilliot, 2013). El problema que se plantea al respecto es el siguiente: cuando se atribuye un predicado a Dios (por ejemplo, Dios es vidente o es oyente), ¿dicho predicado indica algo que es constitutivo de la esencia divina o no? Desde el siglo vIII, algunos teólogos, entre ellos el fundador de los mutazilíes, Wāṣil ibn 'Ațā' de Bașra, negaron la existencia de atributos divinos, pues se abría la posibilidad de que en Dios hubiera algún tipo de composición interna (Wolfson, 1976, pp. 132-133). Sin embargo, otro grupo de mutazilíes aceptó que los atributos funcionaban como adjetivos para describir a Dios. Estos teólogos comenzaron a utilizar el término sifät (proveniente del verbo wasaf = describir) y formularon distintas maneras de comprender qué eran los atributos divinos. Abū l'Hudhayl al-'Allāf (m. 841), por ejemplo, sostuvo que algunos atributos divinos, como el conocimiento, el poder y la vida, eran constitutivos de Dios y sugirió que estaban unidos a 
la esencia divina sin que ello implicara que en Dios había pluralidad (Ash'arī, 2005, pp. 306-311; Gimaret, 2012; Frank, 1969, 1978). En cambio, Abū Hāshim al-Gubbāài (m. 933) sostuvo que en realidad los atributos eran modos (aḩwāl) de la esencia divina, pero no constitutivos de ésta (Gimaret, 1970; Frank, 1971, pp. 85-100; Thiele, 2016).

La postura de Abū Hāshim al-Gubbā'̄ no es fácil de entender: un "modo" no es algo idéntico a la esencia de Dios, pero no se encuentra separado de la esencia divina; por lo tanto, es algo que se predica en relación con la esencia de Dios. Por ejemplo, cuando el conocimiento se predica de Dios, esto no significa que Dios mismo sea conocimiento, sino que el conocimiento es un estado diferente de la esencia de Dios, y puede existir sólo gracias a la esencia divina. Abū Hāshim fue criticado por otros mutazilíes que continuaron rechazando la idea de que los atributos tuvieran una existencia real. Sin embargo, se convirtió en una referencia importante para uno de los teólogos más destacados de la tradición islámica, Ash'arī, quien encontró en esa teoría de los modos una alternativa para defender los atributos reales. Antes, otro teólogo, Ibn Kullāb (m. 854-855), ya había admitido su existencia. Según el propio Ash'arī (2005, 169.10-170.3), Ibn Kullāb sostenía que los atributos divinos son propiedades que pertenecen y subsisten en Dios, no idénticas, pero tampoco completamente diferentes de Él. Ash'arī propuso entonces una concepción muy similar, enfatizando que los atributos divinos no son constitutivos de la esencia de Dios. Para Ash'arī, los atributos ya no son modos (ahweāl) de predicación; el término sifāt (atributo), utilizado habitualmente en la teología de Ash'arī, adquirió un sentido ontológico más fuerte: los atributos son $m a^{\prime} \bar{a} n i$ (sing. $m a^{\prime} n \bar{a}$ ), un término problemático de traducir, pero que en este contexto sugiere "algo que reside o subyace en la esencia divina" (Frank, 1982).

Nótese cómo este modo de comprender los atributos divinos, es decir, como realidades que residen en la esencia de Dios pero no son idénticos a ella, es sumamente parecida a la noción cristiana de hipóstasis (aqānim). ${ }^{15}$ Según Ash'arī, los

${ }^{15}$ Acerca de esta similitud, véase Wolfson, 1956, 1976, pp. 112-32; Griffith, 2002, 2008a, pp. 45-128, 2016; Awad, 2015, pp. 115-266. 
atributos divinos no son idénticos a la esencia de Dios porque esto implicaría que no hay diferencia entre Dios y, por ejemplo, su conocimiento ( $\mathrm{ilm}$ ). Al decir "Dios es conocedor ("álim)", se sugiere que hay un "conocimiento" distinto del "conocedor"; lo que sucede, según Ash'arī, es que el conocimiento no es idéntico a la esencia de Dios, pero reside en ella, de la misma manera en que, según explica Aristóteles en las Categorías, los accidentes ( $a^{\prime} r a \bar{d}$ ) residen en la sustancia (yawhar); sin embargo, en el caso de los atributos divinos, estas propiedades son eternas, como lo es la esencia de Dios.

Harry Wolfson explica justamente que la idea de los atributos divinos entendidos como propiedades inmateriales coexistiendo con Dios desde la eternidad es algo que, según Wạșil ibn 'Atạa', comenzó a discutirse en el siglo viII y fue puesto en duda porque en el Corán no existe pasaje alguno que respalde una postura como ésa. Por ello, explica Wolfson, esa noción de los atributos divinos provino de algún otro lado: de la filosofía griega, del judaísmo o del cristianismo. Wolfson descarta la primera opción: no provino de la filosofía griega porque, según un testimonio de Shahrastānī, la filosofía griega llegó a los círculos mutazilíes cuando ya existía aquella teoría de los atributos divinos; tampoco pudo provenir del judaísmo porque no hay en él una postura como ésa con la que aquellos musulmanes hayan tenido contacto; habría que concluir, por tanto, que esa visión de los atributos divinos provino del cristianismo. Bar Hebraeus (m. 1286), el obispo de la Iglesia ortodoxa siria, explica, según registra Wolfson, que los mutazilíes rechazaron la existencia de atributos divinos reales porque les parecía que era como aceptar las personas o hipóstasis (aqānim) de los cristianos y, en consecuencia, dar coherencia al dogma trinitario: tres personas distintas y al mismo tiempo coexistiendo en una misma (Wolfson, 1956, pp. 1-2).

Wolfson sugiere, entonces, que el origen de la doctrina islámica de los atributos divinos tendría su origen en la doctrina cristiana de la Trinidad. Observa que dos términos árabes son los que suelen utilizarse para referirse a los atributos: $m a^{\prime} n \bar{a}$ y sifät, y se da a la tarea de encontrar si esos términos fueron utilizados por los cristianos árabes al hablar sobre la doctrina de la Trinidad. Descubre así que el término ma'nā lo usó, por 
ejemplo, Ishaq ibn Hunain para traducir el griego pragma, cuyo significado es "cosa". Cuando los cristianos hablan sobre las tres personas de la Trinidad, las describen como hipóstasis (bipostáseis, en siriaco; subsistentiae, en latín), personas (próso$p a$, en siriaco; personae, en latín), sustancias (ousía, en siriaco; substantitae, en latín), pero también usan el término "cosas" (prágmata, en griego; res, en latín). Tal es el caso, como explica Wolfson, de Orígenes, quien se refiere al Padre y al Hijo como dos cosas (prágamta) en hipóstasis, y Tertuliano, quien se refiere a cada una de las tres personas como res substantiva (cosa sustantiva). Aunque el término pragma fue desapareciendo paulatinamente del vocabulario técnico de los teólogos cristianos, Wolfson registra cómo en varios lugares, como en el Concilio de Antioquía (343), en textos de san Basilio y de Cirilo de Alejandría, aparece como equivalente a prosopon e hipóstasis. Abū Qurrah, en un trabajo originalmente escrito en árabe, pero conservado sólo en griego, se refiere a las tres hipóstasis como pragma. Aristóteles, por su parte, usa pragma para describir algo que tiene existencia real y no solamente mental (Wolfson, 1956, pp. 3-5).

En lo que respecta a sifät, este vocablo sí aparece en el Corán para apuntar ciertos términos utilizados para describir a Dios. Sin embargo, no se aclara si esos "atributos" aluden a algo constitutivo de Dios o si son simplemente formas de referirse a Él. Wolfson sugiere que los musulmanes que optaron por creer que los sifät (atributos) eran algo real, pudieron darle este sentido al término a partir de la traducción del griego kharakteristikós empleado por otro cristiano oriental, Juan Damasceno, quien los usó para hablar de las propiedades que hacen distinta a cada una de las tres personas. Juan Damasceno, en efecto, recurrió al término para explicar el principio de diferenciación, según el cual, a pesar de la diferencia, algo puede conservar su unidad (Wolfson, 1956, p. 7). Wolfson extiende su búsqueda principalmente hacia la patrística griega cristiana. En su profundo análisis, llaman la atención las pocas referencias a los cristianos de Oriente cuando, como ha mostrado Hugonnard-Roche (1994), el vocabulario de los árabes depende del trabajo de los traductores siriacos. Por otro lado, la omisión de Wolfson no es extraña si se tiene en cuenta que todavía hay mucho traba- 
jo por hacer acerca de la edición de textos siriacos. Subrayo esto porque el trabajo de estas ediciones aportaría descubrimientos importantes y material complementario que obligaría a la revisión de varios episodios de la historia de la transmisión de textos y de la conformación del vocabulario filosófico y teológico, en una valoración creciente del papel de los cristianos de Oriente.

Aquí me referiré únicamente a la traducción siriaca de las Categorías (Gottheil, 1893; King, 2010) de Aristóteles, pues, a mi juicio, es a partir de este texto que puede vislumbrarse la importancia de los cristianos de Oriente en la discusión islámica de los atributos divinos. No sólo eso: también se observa el modo en que un tratado lógico en concreto, sobre predicados y teoría de la predicación, se usó en una discusión teológica. Las Categorías es uno de los tratados lógicos con mayor número de traducciones y comentarios entre los cristianos de Oriente. Se conservan tres versiones en siriaco: una versión anónima atribuida a Sergius de Resh'aina (m. 536) (Aydin, 2016), la versión de Jacobo de Edesa (m. 708), y la de Jorge, obispo de los árabes (m. 724). Hay también tres manuscritos de la traducción árabe, uno de los cuales, el de la traducción de Hunain ibn Ishaq, pudo haber sido elaborado a partir de un texto en siriaco (King, 2010, pp. 19-29). Existen análisis comparativos sumamente serios sobre las versiones semíticas de este tratado lógico (King, 2010, pp. 80-93; Huggonard-Roche, 2008). No es éste el espacio para hablar de un análisis gramatical y textual tan sofisticado acerca del modo en que la versión siriaca refleja, y a veces guarda distancia de, la versión griega, así como del modo en que la árabe refleja la versión siriaca.

Jacobo de Edesa recurrió al vocabulario filosófico de las Categorías en uno de sus tratados teológicos más importantes, el Enchereidion, en el que se discute precisamente la naturaleza divina. Como ha hecho notar Huggonard-Roche, los términos "naturaleza" (physis, en griego; kyana, en siriaco), "sustancia" (ousía, en griego; ousía, en siriaco), "hipóstasis" (bypostasis, en griego; qnoma, en siriaco), "persona” (prósopon, en griego; parsōp $\bar{a}$, en siriaco) y “especie” (eidos, en griego; 'àdshā, en siriaco), fueron esenciales en las discusiones trinitarias y cristológicas de la patrística tanto griega como oriental (Huggonard-Roche, 
2008). Me detengo sólo en la noción de "hipóstasis" (qnōmā, en siriaco; qunùm, en árabe), término muy debatido en la teología cristiana más temprana, sobre todo en los concilios a los que me he referido líneas arriba, y que se utilizó tanto en la patrística griega como en la siriaca para indicar una naturaleza (physis/ kyana) perfecta e independiente. No explicaré las problemáticas trinitarias y cristológicas ni la cantidad de debates que se suscitaron en el cristianismo alrededor de este tema. Basta con recordar que, en el caso de la discusión cristológica, se trata de determinar, como ya expliqué, si en Cristo puede haber dos naturalezas, la divina y la humana, o si solamente hay alguna de las dos; en el caso de la discusión trinitaria, el problema en cuestión es determinar el modo en que coexisten tres personas en un solo Dios. ¿Cómo defender la existencia de tres personas, tres hipóstasis, sin sacrificar la unidad de Dios? La respuesta es algo técnica: Dios es una única sustancia (ousía, en griego y siriaco; yahwar, en árabe), y en Él coexisten tres hipóstasis distintas.

Puesto en otros términos, hay una distinción conceptual entre sustancia e hipóstasis (Awad, 2015, pp. 118-140). Dicha distinción se desarrolla en el cristianismo en medio de controversias entre los cristianos de Medio Oriente, principalmente nestorianos y antioqueños (estos últimos, partidarios de Calcedonia y del credo en su versión niceoconstantinopolitana). "Sustancia" (ousía, yabwar) remite a la esencia de Dios, a su naturaleza. Por ello, hasta cierto punto es equiparable al término kyama o, en el lenguaje de algunos padres, como san Efrén, itya o ituta (en siriaco), que se refiere al ser de Dios, a la esencia divina. "Hipóstasis", en cambio, se refiere a una sustancia concreta. En este sentido, qnoma nombra un modo de ser de la esencia divina $y$, al mismo tiempo, modos en que

${ }^{16}$ Según el credo niceoconstantinopolitano, hay un solo Dios, pero en Él hay tres personas. Además, se sostiene que la naturaleza humana y la naturaleza divina están unidas (unión hipostática). El Espíritu Santo, la tercera persona, procedía en la primera versión del credo únicamente del Padre. Posteriormente, en la segunda versión establecida en el III Concilio de Toledo (589), se añadió que procedía del Padre y el Hijo. La Iglesia ortodoxa rechazó esta versión y, por ello, se separó definitivamente de la Iglesia romana en 1054.

17 Véase Awad, 2015, pp. 140-150. Para conocer la importancia de san Efrén en la tradición cristiana oriental, véase Griffith, 1998. 
la esencia divina existe de manera particular: Padre, Hijo y Espíritu Santo participan de la sustancia divina. Los tres son distintos entre sí, pero son modos de la misma sustancia divina. El modo en que las tres hipóstasis residen en la misma sustancia divina es análogo al modo como en las Categorías se explica que los accidentes residen en la sustancia: los accidentes no son la sustancia, pero su sustrato sí. Hago notar, sin entrar en detalle, que para comprender la relación entre la sustancia divina y sus hipóstasis, los cristianos añadieron un componente neoplatónico a Aristóteles; a saber: la idea de que en ese caso se trata de una relación eterna y en la que no interviene ningún tipo de materia (King, 2010, pp. 1-14). En este sentido, la relación entre sustancia e hipóstasis es estrictamente metafísica.

Hay cantidad de críticas elaboradas por pensadores musulmanes contra el dogma trinitario, y abundan los argumentos que aseguran que Dios es uno (wähidid). ${ }^{18}$ Por ejemplo, uno de los pensadores mutazilíes más importantes, al-Yabbar (m. 1025), es de los teólogos islámicos que estudió en detalle y debatió las doctrinas cristianas de los nestorianos, los jacobitas y los melquitas. Al-Yabbar (1965, p. 295; 2010, pp. 30-32) reconoce las diferencias entre estos grupos y muestra cómo, a pesar de ello, coinciden en que es posible sostener la trinidad, algo incompatible con la tarwhid o simplicidad divina de los musulmanes: no es posible explicar cómo es que una única sustancia se divide en tres hipóstasis, y mucho menos justificar cuál es la relación entre estas tres; el cristianismo sostiene, en realidad, la existencia de tres dioses. A pesar de lo anterior, la postura estándar musulmana respecto a los atributos divinos, a saber, la de Ash'arī, explicada al inicio de este apartado, es precisamente la misma: Dios es uno, pero en Él subsisten atributos que si bien no son idénticos a El, no existen sino en Él. La similitud entre el dogma trinitario y la doctrina islámica de los atributos divinos respalda la tesis de Wolfson. Sin embargo, he mostrado la necesidad de tener en cuenta un factor ausente en su explicación, esto es, la mediación siriaca de los cristianos

${ }^{18}$ Véase Thomas, 2001, 2002. Para la reacción contra las críticas de los musulmanes, véase Griffith, 2014. 
orientales, sumamente familiar para los filósofos y los teólogos islámicos.

\section{Observaciones finales}

En las secciones precedentes he mostrado la relevancia de la labor de los cristianos orientales en el proceso de transmisión de la filosofía griega. He sostenido que su labor fue indispensable para la recepción de la filosofía en tierras islámicas y he mostrado cómo, a través de la traducción, la adaptación y el desarrollo de terminología filosófica griega al siriaco y luego al árabe, se importaron también algunas formas de comprender determinados conceptos filosóficos que repercutieron en la construcción de argumentos teológicos de las dos tradiciones, la cristiana y la islámica. Sostenía al comienzo que si bien el papel de los cristianos es crucial en la transmisión del pensamiento filosófico, no quiere decir, como afirma Gouguenheim, que la civilización islámica haya tenido un papel meramente receptivo y pasivo. Los filósofos y los teólogos islámicos — como se ve en el ejemplo de los argumentos esgrimidos para resolver la tensión entre la simplicidad de Dios y los atributos divinosdesarrollaron un pensamiento propio inspirado, en efecto, en la filosofía griega y otras fuentes, de la misma forma en que lo hicieron más adelante los filósofos y los teólogos cristianos que conocieron la filosofía griega a través de los comentarios escritos en árabe y traducidos al latín.

He reconstruido brevemente en la tercera sección el proceso de recepción de un texto específico, las Categorías de Aristóteles, con la finalidad de recurrir a un ejemplo concreto del modo en que la terminología griega se retoma y reinterpreta en la discusión de problemas teológicos. De este modo, se ve la forma en que cada tradición, la cristiana y la islámica, se vale de una misma fuente griega para defender sus propias creencias $\mathrm{y}$, al mismo tiempo, debatir entre ellos. Es imperativo tener en cuenta que, en el proceso de transmisión del pensamiento filosófico griego, la mediación siriaca permite comprender la adaptación de varios términos filosóficos griegos que transitaron de manera más natural hacia el árabe a través de la me- 
diación del siriaco, una lengua semítica mucho más cercana al árabe.

Además, desde tiempo atrás, los hablantes del siriaco habían entrado en contacto con la lengua griega. Dada su cercanía con el árabe, el siriaco facilitó el proceso de comprensión de la filosofía griega. Ahora bien, para sostener una conclusión como la anterior, es indispensable revisar en detalle el tránsito del siriaco al árabe. En varios casos hay que comenzar por la reconstrucción de los textos en siriaco (aquellos que existen), revisarlos desde el punto de vista filológico, hacer un análisis comparativo con su equivalente árabe (si se da el caso de que haya dos versiones) y, posteriormente, discutir su contenido filosófico y su impacto en los sectores intelectuales que hayan tenido acceso a él. Como se ve, la recepción de los tratados filosóficos griegos entre los sectores cristianos siriacos y su ulterior transmisión al contexto islámico es un área de estudio de la historia de la filosofía, la filosofía comparada y la historia intelectual de Medio Oriente donde todavía hay mucho trabajo por hacer.

Dirección institucional del autor:

Facultad de Filosofía

Universidad Panamericana

Augusto Rodin, 498

Insurgentes Mixcoac

03920, Ciudad de México, México

\section{Referencias}

Abramowski, L. y Goodman, A. E. (Eds.). (1972). A Nestorian collection of Christological texts (2 vols.). Cambridge: Cambridge University Press.

Adamson, P. (2003). Al-Kindī and the Mu'tazila: Divine attributes, creation and freedom. Arabic Sciences and Philosophy, 13(1), 4577. https://dx.doi.org/10.1017/s0957423903003035

Al-Yabar (1965). Sharh al-'Usul al-Khamsa (Ed. 'Abd al-Karim Uthman). El Cairo: Maktaba Wahba.

Al-Yabar (2010). Critique of Christian origins (Tathbit Dala'il al- 
Nubuwwa). (Eds. y trads. G. S. Reynolds y S. K. Samir). Utah, UT: Brigham University Press.

Anawati, G. e Iskandar, A. Z. (1978). Hunayn ibn Ishāq al-'Ibādī, Abū Zayd. En C. C. Gillispie (Ed.), Dictionary of scientific biography (pp. 230-249), Nueva York, NY: Scribner.

Arkoun, M. (1982). L'bumanisme arabe au IV-X siècle: Miskarwayh, philosophe et historien. París: Vrin.

Arkoun, M. (2005). Humanisme et Islam. París: Vrin.

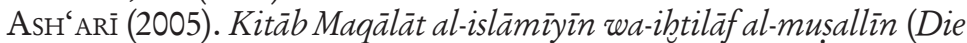
Dogmatischen Lebren der Anbänger des Islam) (Ed. H. Ritter). Berlín: Schwartz.

AwAD, N. G. (2015). Orthodoxy in Arabic terms: A study of Theodore Abu Qurrab's theology in its Islamic context. Boston, MA: De Gruyter.

Aydin, S. (Ed. y trad.). (2016). Sergius of Reshaina. Introduction to Aristotle and his Categories, addressed to Philotheos: Syriac text, with translation and commentary. Leiden: Brill.

BADAWİ, A. (1968). La transmission de la philosophie grecque au monde arabe. París: Vrin.

Baumstark, A. (1900). Aristoteles bei den Syrern. Leipzig: Teubner.

Bergstrasser, G. (1913). Hunain ibn Ishak und seine Schule. Leiden: Brill.

BERGSTRÄSSER, G. (Ed. y trad.). (1925). Hunain ibn Ishāq: Über die Syrischen und Arabishcen Galen-Übersetzungen. Leipzig: Brockhaus.

Bergsträsser, G. (1932). Neue Materialen zu Hunain ibn Ishāà's Galen-Bibliographie. Leipzig: Deutschen Morgenländischen Gesellschaft.

BERTOLACCI, A. (2009). The reception of Averroes' long commentary on the Metaphysics in Latin medieval philosophy until Albertus Magnus. En L. Honnefelder, H. Möhle y S. Bullido del Barrio (Eds.), Via Alberti. Texte-quellen-interpretationen (pp. 457-480). Münster: Aschendorf.

Bertolacci, A. (2011). A new phase of the reception of Aristotle in the Latin west: Albertus Magnus and his use of Arabic sources in the commentaries on Aristotle. En L. Honnefelder (Ed.), Albertus Magnus und der Ursprung der Universitätsidee: Die Begegnung der Wissenschaftskulturen im 13. Jahrhundert und die Entdeckung des Konzepts der Bildung durch Wissenschaft (pp. 259-276). Berlín: Berlin University Press.

Brock, S. (1984). Aspects of translation technique in antiquity. En S. Brock (Ed.), Syriac perspectives on late antiquity (pp. 69-87). Londres: Variorum. 
BROCK, S. (1984a). Some aspects of Greek words in Syriac. En S. Brock (Ed.), Syriac perspectives in late antiquity (pp. 80-108). Aldershot: Variorum.

Brock, S. (1984b). Greek into Syriac and Syriac into Greek. En S. Brock (Ed.), Syriac perspectives in late antiquity (pp. 1-17). Londres: Variorum.

Brock, S. (1992). Syriac historical writing: A survey of the main sources. En S. Brock, Studies in Syriac Christianity: History, literature and theology (pp. 1-30). Hampshire: Variorum.

BRock, S. (1993). The Syriac commentary tradition. En C. Burnett (Ed.), Glosses and commentaries on Aristotelian logical texts: The Syriac, Arabic and Medieval Latin traditions (pp. 3-18). Londres: The Warburg Institute.

Brock, S. (2007) A Syriac intermediary for the Arabic theology of Aristotle? In search of a chimera. En C. D'Ancona (Ed.), The libraries of the neoplatonists (pp. 293-306). Leiden: Brill.

Bruns, P. (Ed.). (2003). Von Athen nach Bagdad: Zur Rezeption griechischer Philosophie von der Spätantike bis zum Islam. Bonn: Borengässer.

BurnetT, C. (2001). The coherence of the Arabic-Latin translation program in Toledo in the twelfth century. Science in Context, 14(1-2), 249-288. https://dx.doi.org/10.1017/S0269889701000096

BurnetT, C. (2005). Arabic into Latin: The reception of Arabic philosophy into Western Europe. En P. Adamson y R. C. Taylor (Eds.), The Cambridge companion to Arabic philosophy (pp. 370404). Cambridge: Cambridge University Press.

ButTERWORTH, C. y Blake, A. K. (Eds.). (1994). The introduction of Arabic philosophy into Europe. Leiden: Brill.

BütTgen, P., De Libera, A., Rashed, M. y Rosier-Catach, I. (2009). Les Grecs, les Arabes et nous : enquête sur l'islamophobie savante. París: Fayard.

COOPERSON, M. (1997). The purported autobiography of Hunayn ibn Ishạ̄. Edebiyāt, 7, 235-249.

D'Alverny, M-Th. (1994). La transmission des textes philosophiques et scientifiques au Moyen Age (Ed. C. Burnett). Norfolk: Variorum.

D'Ancona, C. (2010). The origins of Islamic philosophy. En L. P. Gerson (Ed.), The Cambridge history of philosophy in late antiquity (vol. 2, pp. 869-893). Cambridge: Cambridge University Press. https://dx.doi.org/10.1017/CHOL9780521194846.020

DAIBER, H. (1999). Lateinische Übersetzungen arabischer Texte zur Philosophie und ihre Bedeutung für die Scholastik des Mittelalters: Stand und Aufgaben der Forschung. En J. Hamesse y 
M. Fattori (Eds.), Rencontres de cultures dans la philosophie médiévale : traductions et traducteurs de l'antiquité tardive au $X I V^{\vee}$ siècle (pp. 203-250). Lovaina la Nueva: Université Catholique de Louvain.

De Libera, A. (1997). The Arab forebears of the European renaissance. The UNESCO Courier, 50(2), 4-9.

EL-BIZRI, N. (2008). God: Essence and attributes. En T. Winter (Ed.), The Cambridge companion to classical Islamic theology (pp. 121140). Cambridge: Cambridge University Press. https://dx.doi. org/10.1017/CCOL9780521780582.007

ENDRESS, G. (1997). L'Aristote Arabe: Réception, autorité et transformation du premier maitre. Medioevo, (23), 1-42.

EndRess, G. (1997a). The circle of al-Kindī. Early Arabic translations from Greek and the rise of Islamic philosophy. En G. Endress y R. Kruk (Eds.), The ancient tradition in Christian and Islamic Hellenism (pp. 43-76). Leiden: Research School cNws.

FIDORA, A. (2003). Die Wissenschaftstheorie des Dominicus Gundissalinus. Berlín: Akademie.

FIDORA, A. (2013). From Arabic into Latin into Hebrew: Aristotelian psychology and its contribution to the rationalisation of theological traditions. En L. X. López-Farjeat y J. A. Tellkamp (Eds.), Philosophical psychology in Arabic thought and the Latin Aristotelianism of the $13^{\text {th }}$ century (pp. 17-39). París: Vrin.

Fidora, A. y Polloni, N. (Eds.). (2017). Appropriation, interpretation and criticism: Philosophical exchanges between the Arabic, Hebrew and Latin intellectual traditions. Turnhout: Brepols.

FRANK, R. M. (1969). The divine attributes according to the teachings of Abū l-Hudhayl al-'Allaf. Le Muséon, 82, 451-506.

Frank, R. M. (1971). 'Abū Hāshim's Theory of 'States': Its structure and function. En Actas do IV Congresso de Estudos Arabes e Islamicos. Coimbra, Lisboa 1 a 8 setembro de 1968 (pp. 85-100). Leiden: Brill.

FRANK, R. M. (1978). Beings and their attributes: The teaching of the Basrian School of the Mu'tazila in the classical period (studies in Islamic philosophy and science). Albany, NY: State University of New York Press.

Frank, R. M. (1982). Attribute, attribution, and being: Three Islamic views. En P. Morewedge (Ed.), Philosophies of existence: Ancient and medieval (pp. 258-278). Nueva York, NY: Fordham University Press.

Galluzzo, G. (2013). The medieval reception of Book Zeta of Aristotle's Metaphysics (2 vols.). Leiden: Brill. 
Gilliot, C. (2013). Attributes of God. En K. Fleet, G. Krämer, D. Matringe, J. Nawas y E. Rowson (Eds.), Encyclopaedia of Islam (THREE). http://dx.doi.org/10.1163/1573-3912_ei3_COM_ 0163

Gimaret, D. (1970). La théorie des aḥwāl d'Abū Hāšsim al-Ğubbā'ī d'après des sources aš'arites. Journal Asiatique, 258, 47-86.

Gimaret, D. (2012). Mu'tazila. En P. Bearman, Th. Bianquis, C. E. Bosworth, E. van Donzel y W. P. Heinrichs (Eds.), Encyclopaedia of Islam (2a ed.). https://dx.doi.org/10.1163/1573-3912_islam COM 0822

GotTheIL, R. J. H. (1893). The Syriac versions of the Categories of Aristotle. Hebraica, 9(3-4), 166-215.

GouguenheIm, S. (2008). Aristote au Mont Saint-Michel: les racines grecques de l'Europe chrétienne. París: Seuil.

GrIFFITH, S. H. (1998). A spiritual father for the whole church: The universal appeal of St. Ephraem the Syrian. Hugoye: Journal of Syriac Studies, 1(2), 197-220.

GrIFFITH, S. H. (2002). Melkites, Jacobites, and the Christian controversies in Arabic in third/ninth-century Syria. En D. Thomas (Ed.), Syrian Christians under Islam: The first thousand years (pp. 9-55). Leiden: Brill.

Griffith, S. H. (2008). Hunayn ibn Ishāa and the Kitāb Ādāb alFalāsifah: The pursuit of wisdom and a humane polity in early Abbasid Baghdad. En G. A. Kiraz (Ed.), Malphono w-Rabo dMalphone: Studies in honor of Sebastian P. Brock (pp. 135-160). Piscataway, NJ: Gorgias Press.

GrIfFITH, S. H. (2008a). The church in the shadow of the mosque: Christians and Muslims in the world of Islam. Princeton, NJ: Princeton University Press.

GRIFFITH, S. H. (2014). The unity and trinity of God: Christian doctrinal development in response to the challenge of Islam-A historical perspective. En M. Root y J. J. Buckley (Eds.), Christian theology and Islam (pp. 1-30). Oregon, OR: Cascade Books.

GRIFFITH, S. H. (2016). Excursus I: Christian theological thought during the first Abbāsid century. En S. Schmidtke (Ed.), The Oxford handbook of Islamic theology (pp. 91-102). Oxford: Oxford University Press. https://dx.doi.org/10.1093/oxford$\mathrm{hb} / 9780199696703.013 .003$

Gutas, D. (1998). Greek thought, Arabic culture: The Graeco-Arabic translation movement in Baghdad and early 'Abbāsid society (2 ${ }^{\text {nd. }}$ $4^{\text {th }} / 8^{\text {th }}-10^{\text {th }}$ centuries). Nueva York, NY: Routledge.

Hasse, D. K. (2014). Influence of Arabic and Islamic philosophy on 
the Latin West. En E. N. Zalta (Ed.), The Stanford encyclopedia of philosophy (edición de otoño de 2014). Recuperado de https:// plato.stanford.edu/archives/fall2014/entries/arabic-islamicinfluence/

Hasse, D. N. (2000). Avicenna's De Anima in the Latin West: The formation of a peripatetic philosophy of the soul 1160-1300. Londres: The Warburg Institute.

Hasse, D. N. (2016). Success and suppression: Arabic sciences and philosophy in the Renaissance. Cambridge, MA: Harvard University Press.

Hasse, D. N. y Bertolacci, A. (Eds.). (2012). The Arabic, Hebrew and Latin reception of Avicenna's metaphysics. Berlín: Walter de Gruyter.

Hourani, A. (1991). History of Arab peoples. Cambridge, MA: The Belknap Press of Harvard University Press.

Huggonard-Roche, H. (1990). Les traductions du grec au syriaque et du syriaque à l'arabe (à propos de l'Organon d'Aristote). En J. Hamesse y M. Fattori (Eds.), Rencontres de cultures dans la philosophie médiévale: Traductions et traducteurs de l'antiquité tardive au XIV siècle (pp. 131-147). Lovaina la Nueva: Université Catholique de Louvain.

Huggonard-Roche, H. (1991). L'intermédiaire syriaque dans la transmission de la philosophie grecque à l'arabe: le cas de l'Organon d'Aristote. Arabic Sciences and Philosophy, 1(2), 187209. https://dx.doi.org/10.1017/S095742390000148X

HuggonARD-Roche, H. (1993). Remarques sur la tradition arabe de l'Organon d'après le manuscrit Paris, Bibliothèque nationale, ar. 2346. En C. Burnett (Ed.), Glosses and commentaries on Aristotelian logical texts: The Syriac, Arabic and Medieval Latin traditions (pp. 19-28). Londres: The Warburg Institute.

HuggONARD-Roche, H. (1994). La formation du vocabulaire de la logique en arabe. En D. Jacquart (Ed.), La formation du vocabulaire scientifique et intellectuel dans le monde arabe (pp. 22-38). Turnhout: Brepols.

Huggonard-Roche, H. (2008). Jacob of Edessa and the reception of Aristotle. En B. T. H. Romeny (Ed.), Jacob of Edessa and the Syriac culture of his day (pp. 205-222). Leiden: Brill. https://doi. org/10.1163/ej.9789004173477.i-314.90

IBN ABū UșAYBI'A (1965). Uyūn al-anbā’ fì tabakāt al-atỉbbā (Ed. Nizār Riḍ̄à) (vol. 2, pp. 257-259). Beirut: Dāa Maktabat al Hayāt.

Janssens, J. (2007). The reception of Avicenna's Physics in the Latin Middle Ages. En A. Vrolijk y J. P. Hogendijk (Eds.), Ob ye 
gentlemen: Arabic studies on science and literary culture in bonour of Remke Kruk (pp. 55-64). Leiden: Brill.

Joose, P. N. (2004). Syriac encyclopaedia of Aristotelian philosophy: Barbebraeus $13^{\text {th }}$ C., Butyrum Sapientia. Books of ethics, economy and politics. Leiden: Brill.

KInG, D. (Trad.). (2010). The earliest Syriac translation of Aristotle's Categories. Leiden: Brill.

Laughlin, B. (1995). The Aristotle adventure: A guide to the Greek, Arabic, and Latin scholars who transmitted Aristotle's logic to the Renaissance. Flagstaff, AZ: Albert Hale Publishing.

Monferrer S., J. P. (2005). “Apologética racionalista” de Abū Qurrah en el Maymar fi wuyūd al-Hāliq wa-l-dīn al-qawìm II/2, 12-14. Anales del Seminario de Historia de la Filosofía, 22, 41-56.

Penn, M. P. (2015). Envisioning Islam, Syriac Christians and the Muslim world. Filadelfia, PA: University of Pennsylvania Press.

RAsHed, R. (Ed.). (2009). Thäbit ibn Qurra. Science and philosophy in ninth-century Bagdhad. Berlín: Walter de Gruyter.

Schmieja, H. (2012). Arabic-Latin reception of Aristotle's Physica and Averroes' Commentarium magnum: Two versions in a manuscript from Toledo. Oriens, 40(1), 149-167. https://dx.doi. org/10.1163/187783712X634698

Schмiтt, J. O. (Ed. y trad.). (2013). Barhebraeus, Butyrum Sapientiae, Physics. Leiden: Brill.

SCHÖFfLER, H. H. (1980). Die Academie von Gondischapur: Aristoteles aufdem Wege in den Orient. Stuttgart: Verlag Freies Geistesleben.

Sezgrn, F. (Ed.). (1996). Yūhannāūha Māsawayh (d.243/857): Texts and studies. Fráncfort del Meno: Institute for the History of Arabic-Islamic Science.

Sezgrn, F. (Ed.). (1999). Hunayn ibn Ishạa (d. 260/873): Texts and studies. Fráncfort del Meno: Institute for the History of ArabicIslamic Science.

Strohmaier, G. (2012). Hunayn b. Ishāạ al-'Ibādī. En P. Bearman, Th. Bianquis, C. E. Bosworth, E. van Donzel y W. P. Heinrichs (Eds.), Encyclopaedia of Islam (2a. ed.). https://dx.doi. org/10.1163/1573-3912_islam_COM_0300

TAKAHASHI, H. (Ed. y trad.). (2003). Aristotelian meteorology in Syriac: Barbebraeus, Butyrum Sapientiae, books of mineralogy and meteorology. Leiden: Brill.

TAKAhashi, H. (2015). Syriac as the intermediary in scientific Graeco-Arabica: Some historical and philological observations. Intellectual History of the Islamicate World, 3(1-2), 66-97. https:// dx.doi.org/10.1163/2212943X-00301004 
Thiele, J. (2016). Abū Hāshim al-Jubbā'î̀s (d. 321/933) theory of 'states' (abwāl) and its adaptation among Ash'arite theologians. En S. Schmidtke (Ed.), The Oxford handbook of Islamic theology (pp. 264-383). Oxford: Oxford University Press.

Thomas, D. (2001). The doctrine of the Trinity in the early Abbasid era. En L. Ridgeon (Ed.), Islamic interpretations of Christianity (pp. 78-98). Londres: Routledge.

Thomas, D. (2002). Early Muslim polemic against Christianity: Abù 'İsā al-Warrāq's 'against the incarnation'. Cambridge: Cambridge University Press.

Treiger, A. (2014). Palestinian origenism and the early history of the Maronites: In search of the origins of the Arabic theology of Aristotle. En D. Janos (Ed.), Ideas in motion in Baghdad and beyond: Philosophical and theological exchanges between Christians and Muslims in the third/ninth and fourth/tenth centuries (pp. 4480). Leiden: Brill.

VagelPohl, U. (2008). Aristotle's Rhetoric in the East: The Syriac and Arabic translation and commentary tradition. Leiden: Brill.

Vagelpohl, U. (2010). The Prior Analytics in the Syriac and Arabic tradition. Vivarium, 48(1), 134-158. https://dx.doi.org/10.1163/ 156853410X489745

WATT, J. W. (Ed.). (2005). Aristotelian Rhetoric in Syriac: Bar Hebraeus, Butyrum Sapientiae, Book of Rhetoric. Leiden: Brill.

Watт, J. W. (2008). Al-Fārābī and the history of the Syriac Organon. En G. A. Kiraz (Ed.), Malphono w-Rabo d-Malphone: Studies in honor of Sebastian P. Brock (pp. 751-778). Piscataway, NJ: Gorgias Press.

WatT, J. W. (2010). Christianity in the renaissance of Islam. Abū Bishr Mattā, al-Fārābī, and Yahyā Ibn 'Adī. En Rhetoric and philosophy from Greek into Syriac (pp. 99-112). Londres: Routledge.

Wolfson, H. A. (1956). The Muslim attributes and the Christian Trinity. Harvard Theological Review, 49(1), 1-18. https://doi. org/10.1017/S0017816000028066

Wolfson, H. A. (1959). Philosophical implications of the problem of the divine attributes in the Kalam. Journal of the American Oriental Society, 79(2), 73-80.

Wolfson, H. A. (1976). The philosophy of the Kalam. Cambridge, MA: Harvard University Press.

Zimmerman, A. y Craemer-Ruegenberg, I. (Ed.). (1985). Orientalische Kultur und Europäisches Mittelalter. Berlín: Walter de Gruyter. 
